\title{
Pesquisa e desenvolvimento tecnológico na indústria
}

\author{
José Mindlin, diretor do Departamento de \\ Comércio Exterior da FIESP e presidente da \\ Metal Leve
}

Estamos ainda em fase incipiente de um processo autônomo de desenvolvimento tecnológico na indústria. Poucas são as empresas que fazem pesquisas próprias no Brasil, embora seja muito grande o campo no nosso parque industrial. Fala-se da empresa nacional; se a estrangeira também apresenta pouca pesquisa própria, isso deriva de fatores bem diversos, que poderiam ser alterados. Mas as posições são diferentes.

A importância de um setor de pesquisa e desenvolvimento nas indústrias é manifesta. Antes de tudo, cumpre reconhecer que a tecnologia é um bem econômico de fundamental importância como fator de progresso e de melhoria das condiç̃es de vida. Por ser bem escasso, sobre o qual agem as leis da oferta e da procura, possui preço de mercado geralmente imposto pelo seu detentor. Pouco adianta criticar esse fato e sugerir que a tecnologia não deverá ser considerada fonte de lucro material, e, sim, de uso coletivo. Os países industrializados, que progridem muito mais rapidamente na aquisição de conhecimentos tecnológicos do que os em desenvolvimento, é óbvio que impõem as regras do mercado. O que cumpre, assim, é absorver o máximo possível a tecnologia externa e formar gradualmente potencial material e humano que permita realização de pesquisa tecnológica própria. A evolução inicia-se pela aquisição do know-how, que, absorvido, conduz inevitavelmente à indagação do know-how. Aquele atende às necessidades de engenharia de produção e de processo, sem maior aprofundamento; este, à pesquisa e ao desenvolvimento.
Em um país como o nosso, a diversidade de situações é grande. Temos uma gama de empresas que empregam tecnologia, desde as pequenas fábricas, que o fazem rudimentarmente, até as grandes indústrias, já produtoras de bens de alta sofisticação. A decisão de incluir, numa fábrica, um setor de pesquisa e desenvolvimento não é fácil. Exige porte industrial capaz de justificar os gastos e riscos envolvidos, pois queimar etapas oferece perigos, tanto do ponto de vista financeiro, como organizacional. Enquanto a empresa não atinge estágio capaz dessa inovação é preferível recorrer à tecnologia externa, seja alienígena ou nativa, o que não exclui, entretanto, esforço paralelo da tecnologia própria, a ser desenvolvido em escala crescente, embora sem grande pretensão inicial. É quase supérfluo enumerar as vantagens proporcionadas pela pesquisa e desenvolvimento na indústria, mas convém salientar sua importância para estimular o advento de clima propício à criatividade e eliminar certas características organizacionais negativas, entre os quais o receio e a desconfiança em relação a qualquer tipo de mudança.

É claro que a introdução do setor de pesquisa e desenvolvimento na indústria modifica rotinas e exige disposição de aceitar mudanças. Em primeiro lugar, cabe considerar o caráter permanente de absorção de tecnologia em qualquer indústria, pois quanto maior for o preparo tecnológico melhores serão os resultados e mais eficientemente se processará a absorção de tecnologia externa ainda necessária (note-se que o desenvolvimento de um traba- 
Iho de pesquisa e desenvolvimento - PGD, não exclui, em absoluto, a busca de tecnologia externa, porque o ritmo de pesquisa dos países mais desenvolvidos é incomparavelmente mais intenso do que o nosso, a curto ou médio prazos). Assim sendo, devemos procurar beneficiar-nos de tudo quanto se faça no exterior em matéria de pesquisa tecnológica, ao lado do nosso maior esforço para criação de tecnologia própria. Pensar em termos de substituição de uma por outra seria de certo desastroso no momento em que o país procura conquistar mercados externos e se inserir no contexto mundial.

Outras vantagens óbvias de desenvolvimento de pesquisa própria consistem na possibilidade de se estabelecer intercâmbio interno e externo proveitoso, com fontes apropriadas, através do contato da indústria com institutos de pesquisa e universidades; na maior facilidade de determinação do justo valor para a compra de tecnologia; no conhecimento das repercussões econômicas e financeiras de disposicões contratuais que vão além da tecnologia, estendendo-se ao controle do processo de industrialização e comercialização da empresa adquirente de tecnologia. Em outras palavras, a criação de tecnologia própria, além de promover melhoria interna permite melhor identificação de fontes de conhecimento ou fornecimento de tecnologia externa, reduz a dependência tecnológica, e proporciona condições de diálogo em nível adequado. Nossas empresas, de modo geral, atravessaram décadas preocupadas com os problemas do dia-a-dia, sem possibilidade de visão prospectiva do futuro. Para conseguir disseminar a idéia de PGD no meio industrial existem várias maneiras: em primeiro lugar, um trabalho de catequese e incentivo por parte das autoridades, coadjuvadas pelas entidades empresariais, pode trazer resultado positivo. O processo é comparável ao das exportações de manufaturados, que o empresariado foi induzido a empreender através de uma série de incentivos que produziram resultados espetaculares. Já existem hoje financiamentos favoráveis para a implantação de centros de pesquisa e desenvolvimento. Mas isto não basta; seria necessário, ainda, um programa de incentivos fiscais, permitindose dedução pelo menos em dobro das despesas efetuadas em pesquisa tecnológica. O mecanismo deveria ser elaborado com cuidado, para evitar fraudes, mas a preocupação maior deveria ser estimuladora, e não policial. Confiança a priorie severidade a posteriori devem funcionar satisfatoriamente. Pesquisadores só se formam fazendo pesquisa, e a criação de recursos humanos nesse campo fará muito mais do que reduzirnossa dependência, pois permitir-nosá absorver melhor a tecnologia externa e criar tecnologia própria, levando-nos ao estágio almejado; o de ser um grande importador e grande exportador de tecnologia.
Além de incentivos fiscais, e do apoio de organismos como a Financiadora de Estudos e Projetos - Finep, articulada com o Conselho Nacional de Desenvolvimento Científico e Tecnológico - CNPq e o Banco Nacional de Desenvolvimento Econômico e Social - BNDES, também o Instituto Nacional da Propriedade Industrial - INPI, pode exercer no campo de desenvolvimento tecnológico um papel importante, transmitindo aos usuários potenciais o conhecimento de tecnologias existentes no exterior, e facilitando a aquisição, pela empresa brasileira, de tecnologia externa. Na tarefa de exame dos contratos de transferência de tecnologia, poderia o INPI valer-se dos institutos de pesquisa existentes, e mesmo da colaboração da própria indústria, através de técnicos por ela colocados à disposição desse órgão, e igualmente, através de um conselho de empresários.

Não basta, entretanto, querer importar tecnologia, é preciso que seu detentor esteja disposto a fornecê-la, e isso nem sempre é o caso. Algumas empresas dos países industrializados pura e simplesmente preferem estabelecer-se aqui, continuando a realizar pesquisas unicamente em seus países de origem, sem qualquer transferência tecnológica ao nosso país. Outras exigem associações com os pretendentes à aquisição de tecnologia, para participar do crescimento do mercado. Isto em si pode não representar inconveniência para nós, desde que resulte de efetivo acordo entre as partes, mas não parece que seja sadia uma associação imposta como condição de transferência de tecnologia.

O problema de fato existe. Desde o momento em que o Brasil iniciou esforço de exportação de manufaturados, e alcançou sucesso, as dificuldades no fornecimento de tecnologia começaram a surgir. Fornecer know-how para fabricação e venda no mercado interno brasileiro, é uma coisa, proporcionar condições à empresa brasileira de concorrer no exterior com a prestadora de tecnologia, é coisa muito diversa. Intensificou-se o registro de patentes e restringiuse a venda de know-how (medida de defesa compreensível, mas de curta visão, e de eficácia muito relativa). Dir-se-ia até que, no Brasil, serviu de estímulo ao desencadeamento do esforço de buscar tecnologia própria, e, nesse sentido, até nos beneficiou. Mas não vejo por que o assunto deva necessariamente ser encarado como fonte de atrito. O desenvolvimento da empresa brasileira e a ampliação de seu campo de atividade deveriam ser vistos e aceitos como fenômeno normal de crescimento. No momento em que atingimos certa maturidade industrial, parece que um esquema de cooperação seria muito mais proveitoso, para ambos os lados, que um esquema de luta. Além dos acordos de assistência técnica, deveriam ser estimulados acordos de cooperação tecnológica, em que, ao invés de pagamen- 
to de royalty, houvesse rateio de despesas, com pesquisas realizadas aqui e no exterior, e acesso recíproco a umas e outras, de pesquisadores estrangeiros e brasileiros.

O problema nesse campo está ligado à questão da legislação sobre capital estrangeiro. Não creio que se consiga obter transferência de tecnologia de ponta no quadro atual, em que existe praticamente liberdade total de investimento em qualquer setor, com pouquíssimas exceções. Basta que uma empresa estrangeira não pleiteie incentivos para que ela possa se instalar no Brasil, com vistas a uma presença no mercado brasileiro atual e futuro. Acuidade não falta à empresa estrangeira para saber que esse mercado representa um potencial enorme. Cabe a nós, através de legislação que permita seletividade do investimento externo, estabelecer condições que assegurem vantagens recíprocas, entre as quais se destacaria, para o lado brasileiro, a exigência de realização de pesquisa no Brasil e do recebimento de tecnologia aberta, e, do lado do investidor, a participação do mercado e a segurança da estabilidade das regras estabelecidas. O ideal seria um entendimento que proporcionasse aos nossos técnicos o acesso à pesquisa realizada no exterior e, também, na realização de pesquisa no Brasil por parte das empresas estrangeiras, a participação de técnicos brasileiros. Porque, na realidade, a empresa estrangeira praticamente não faz pesquisa no Brasil, e para aquien- via pacotes fechados, o que, no estágio atual de nosso desenvolvimento, não parece razoável. Adotado que fosse um esquema de cooperação, teríamos a vantagem de um conhecimento mais amplo e da formação de recursos humanos altamente qualificados, permitindo-nos absorver tecnologia cada vez mais sofisticada. Do lado do investidor poderia parecer uma desvantagem partilhar essa tecnologia, mas, na realidade, não vejo o assunto sob esse prisma. A empresa estrangeira, além de ter nossa participação num rateio de despesas de pesquisa, estimularia a criatividade do lado brasileiro, o que amanhã lhe permitiria auferir vantagens de know-how desenvolvido no Brasil.

A atual conjuntura brasileira não é favorável a alterações na legislação sobre o investimento externo, mas nem por isso o problema e suas possíveis soluções deve deixar de ser colocado, tanto mais que as medidas que sugiro não representam, em absoluto, qualquer tipo de antagonismo à empresa estrangeira. Fala-se muito em aprofundar e acelerar o chamado diálogo norte-sul entre os países industrializados e em desenvolvimento, e isso, parece, é um imperativo para a solução dos graves problemas socias que nos afetam. Ora, a aproximação no campo tecnológico é, sem dúvida alguma, um dos fatores mais importantes da efetividade desse diálogo, e nela reside uma grande esperança, que não deveria ser frustrada.

\section{Transferência de tecnologia e exportação}

Arthur Carlos Bandeira, presidente do Instituto Nacional da Propriedade Industrial - INPI, do Ministério da Indústria e Comércio - MIC.
Arthur Carlos Bandeira

apresentar-se-ão alguns problemas e sugestões para o campo da exportação.

A exportação de tecnologia pode induzir à exportação de insumos, componentes, máquinas e equipamentos. Há, porém, que se atentar para o fato de que o país receptor da tecnologia somente realizará a transação se o saldo de divisas Ihe for favorável. Expliquemos: os pagamentos ao exterior por determinada tecnologia, bem como pelas necessidades de se importarem máquinas e equipamentos deverão sempre ser inferiores aos gastōs das importações que foram substituídas. De certa maneira, o fornecedor de tecnologia terá o seu lucro diminuí- 